\title{
Front Matter: Volume 10305
}

, "Front Matter: Volume 10305," Proc. SPIE 10305, Dosimetry of Laser Radiation in Medicine and Biology, 1030501 (10 January 1989); doi: $10.1117 / 12.2283582$

SPIE. Event: Institutes for Advanced Optical Technologies, 1988, Berlin, Germany 


\section{Preface}

The concept of the Institutes for Advanced Optical Technologies developed out of SPIE's desire to foster increased interaction and collaboration among researchers working in emerging optical technologies. The Institutes provide a forum for experts in these areas to analyze and document the state of the art and to point toward future trends and applications. Institute topics are selected for their timeliness as well as their significance to future progress in the application of optics. Institute organizers invite selected experts to participate as paper contributors and discussion participants. It is intended that the interaction generated by the small group structure in a retreat-type setting will foster productive discussions that are beyond the scope and possibility of a regular conference format.

Each Institute has two primary objectives: first, that the interactions and dialogue stimulate technical advancement, and second, that the publication of the Institute book results in an authoritative collection of significant papers covering key topics in the field. While each editor and committee has unique criteria for determining the acceptability of contributions, it is intended that the Institute process itself will establish the worth and appropriateness of the individual contributions. Each contributor is asked to prepare a draft manuscript and circulate it to the other participants in advance of the Institute. The editor/chair organizes an agenda for discussing critical technical issues. The interactions and congenial discussions by the Instituite members are the basis for the ensuing Institute volume. The final action of the Institute is to decide the scope of the volume and what material is to be included and what other material is to be added and by whom.

This volume exemplifies the second goal of the Institute, which in this case is to present an authoritative publication emphasizing the dosimetry and tissue interaction of laser radiation. Sections cover laser-tissue interaction, laser systems and delivery systems, photodynamic therapy, national and international laser safety regulations and standards, therapeutic guidelines, and training issues.

In November-December 1988 the participants met during a three-day period in Berlin for this Institute on Dosimetry of Laser Radiation in Medicine and Biology. Individual participants led discussions based on their expertise and interests. These discussions permitted all participants to reinforce, disagree, or gain new insights into this important field. It also gave contributors and the editorial committee opportunities to assess how close the overall contributions came to their expectations.

Roy F. Potter

General Editor, SPIE Institute for Advanced Optical Technologies

Dosimetry of Laser Radiation in Medicine and Biology, edited by Gerhard Mueller, David Sliney,

Roy Potter, Proc. of SPIE Vol. 10305 (Vol. IS05), 1030501 - (c) (1989) 2017 SPIE

CCC code: $0277-786 \mathrm{X} / 17 / \$ 18 \cdot$ doi: $10.1117 / 12.2283582$ 
Other publications in the SPIE Institutes for Advanced Optical Technologies series:

Transformations in Optical Signal Processing, William T. Rhodes, James R. Fienup, Bahaa E. A. Saleh, Editors, 1984, SPIE Volume 373 (Out of print)

Optical and Hybrid Computing, Harold H. Szu, Editor, 1987, SPIE Volume 634

Photonics: High Bandwidth Analog Applications, James Chang, Editor, 1987, SPIE Volume 648

Large-Area Chromogenics: Materials and Devices for Transmittance Control, Carl M. Lampert, Claes G. Granqvist, Editors, 1989, Volume IS 4 


\section{Dosimetry of Laser Radiation in Medicine and Biology}

\section{Contents}

Part One

Introduction

Part Two

Dosimetry in

Medical Applications

Part Three

Radiometric and

Photometric Basics

\section{Part Four}

Theoretical Calculations and Modeling

\author{
Preface \\ Institute Participants \\ Introduction
}

2 Laser light interaction with biomolecules, cells, and tissue

V. S. Letokhov, Institute of Spectroscopy/Academy of Sciences (USSR)

5 Need for dosimetry in medical treatment

D. H. Sliney, U.S. Army Environmental Hygiene Agency (USA)

10 How to define dosimetry for laser treatment: the black box approach

K. Dörschel, G. J. Müller, Laser-Medizin-Zentrum GmbH, Berlin (FRG)

16 Dosimetric concepts for optical radiation

D. H. Sliney, U.S. Army Environmental Hygiene Agency (USA)

23 Light dosimetry as compared to ultrasound and other nonionizing radiation

P. Greguss, Technical Univ. Budapest (Hungary)

38 Quantities and units of optical radiation and their measurement

E. Sutter, Physikalisch-Technische Bundesanstalt (FRG)

80 Actinic radiation and its principles of measurements

E. Krochmann, J. Krochmann, PRC Krochmann GmbH (FRG)

102 Monte Carlo model of light propagation in tissue

S. A. Prahl, Univ. of Texas/Austin (USA); M. Keijzer, S. L. Jacques, Harvard Medical School (USA); A. J. Welch, Univ. of Texas/Austin (USA)

114 Optics of tissue

L. O. Svaasand, Univ. of Trondheim (Norway); C. J. Gomer, Children's Hospital of Los Angeles (USA)

133 Thermotics of tissue

L. O. Svaasand, Univ. of Trondheim (Norway); C. J. Gomer, Children's

Hospital of Los Angeles (USA); A. J. Welch, Univ. of Texas/Austin (USA)

146 Comparing the P3-approximation with diffusion theory and with Monte Carlo calculations of light propagation in a slab geometry

W. M. Star, Dr. Daniel den Hoed Cancer Ctr. (Netherlands) 
Part Five Applied Dosimetry
Spot-size dependence of laser retinal dosimetry

D. Courant, L. Court, Ctr. d'Etudes Nucléaires (France); D. H. Sliney,

U.S. Army Environmental Hygiene Agency (USA)

166 Does comprehension of laser therapy in portwine stains require biology in addition to physics?

M. J. C. van Gemert, Experimental Laser Ctr./Academic Medical Ctr. (Netherlands)

172 Beam delivery systems

M. J. Colles, Heriot-Watt Univ. (UK)

175 Dynamic filters for protective devices

E. Buhr, E. Sutter, Physikalisch-Technische Bundesanstalt (FRG)

196 Miniature spectroradiometer for dosimetry

P. Eriksen, National Institute of Occupational Health (Denmark)

203 Applied dosimetric measurements

P. Greguss, Technical Univ. Budapest (Hungary)

216 Dosimetry for photocoagulation by the use of autofluorescence

T. Brodzinski, K. Dörschel, G. J. Müller, Laser-Medizin-Zentrum $\mathrm{GmbH}$, Berlin (FRG)

226 Dosimetry for photoablation technique

K. Dörschel, G. J. Müller, Laser-Medizin-Zentrum GmbH, Berlin (FRG)

238 Survey of interaction mechanisms, dosimetry, and safety concepts in YAG laser ophthalmic photodisruption

F. Docchio, Univ. degli Studi di Brescia and CNR (Italy); A. Avigo, R. Palumbo, Univ. degli Studi di Brescia (Italy); D. H. Sliney, U.S. Army Environmental Hygiene Agency (USA) 


\section{Institute Participants}

Dr. E. Buhr

Physikalisch-Technische Bundesanstalt

Abt. 4 - Optik

Bundesallee 100

3300 Braunschweig

FRG

Dr. M. J. Colles

Medical Laser Unit

Research Park, Riccarton

Edinburgh EH 14 4AP

United Kingdom

Dr. Daniel Courant

Commissariat a l'Energie Atomique

DPS/SPE

BP no. 6

92265 Fontenay aux Roses Cedex

France

Dr. K. Dörschel

Laser-Medizin-Zentrum GmbH, Berlin

Krahmerstr. 6-10

1000 Berlin 45

FRG

Dr. Paul Eriksen

Danish National Institute of Occupational Health

Lerso Parkalle 105

2100 Copenhagen 0

Denmark

Dr. Martin J. C. van Gemert

Experimental Laser Centre

Academisch Ziekhuis bij de U.v.A.

Meibergdreef 9

1105 AZ Amsterdam Zuidoost

Netherlands

Prof. Dr. Pal Greguss

Applied Biophysics Laboratory

Technical University Budapest

Stoczek u. 2.St. ep.I.em

1111 Budapester

Hungary

Prof. Dr. Jürgen Krochmann

Licht- und Strahlungsmeßtechnik

Geneststr. 6

1000 Berlin 62

FRG

Prof. Dr. G. J. Müller

Laser-Medizin-Zentrum GmbH, Berlin

Krahmerstr. 6-10

1000 Berlin 45

FRG
Dr. Roy F. Potter

SPIE

P.O. Box 10

Bellingham, WA 98227-0010

USA

Dr. David H. Sliney

U.S. Army Environmental Hygiene Agency

406 Streamside Drive

Fallston, MD 21047-6900

USA

Dr. Willem M. Star

Dr. Daniel den Hoed Kliniek

Groene Hilledijk 301

P.O. Box 5201

3008 AE Rotterdam

Netherlands

Dr. Ernst Sutter

Physikalisch-Technische Bundesanstalt

Abt. 4 - Optik

Bundesallee 100

3300 Braunschweig

FRG

Prof. Dr. Lars O. Svaasand

University of Trondheim

Division of Physical Electronics

Trondheim N 7034 NTH

Norway

Prof. A. J. Welch

The University of Texas at Austin

Bio-Medical Engineering Lab.

Engineering-Science Building 639

Austin, TX 78712

USA

\section{Guest Contributors}

Dr. Franco Docchio

Dept. of Industrial Automation

University of Brescia

Via D. Valotti 9

25060 Mompiano/BS

Italy

Dr. V. S. Letokhov

Institute of Spectroscopy

Academy of Science

Moskau, Region Troizk 142092

USSR 


\section{Dosimetry of Laser Radiation in Medicine and Biology}

\section{Introduction}

Since 1962, laser radiation has been used in various clinical fields for treatment. From the beginning, clinicians looked for immediate evidence of laser-tissue interaction, for example, coagulation indicated by blanching of the irradiated tissue, some informatory response indicated by reddening of the tissue, or, in the worst case, the occurrence of blisters. At higher power densities, laser radiation has been used for tissue evaporation (cutting), indicated by the amount of tissue removed and by charring at the cutting edges. Even in relatively new applications such as photodisruption in ocular treatment, the physician looks for microscopic disruption and removal of the target tissue.

During these 27 years of laser treatment in medicine, only a very few papers have pointed out the need for on-line measurements of the laser-induced biological result in order to develop a closed-loop system to achieve a higher safety standard and reproducibility of therapeutic guidelines for the administration of laser power. Conversely, the question of dosimetry for ionizing radiation has been investigated extensively in the field of $x$-ray diagnostics and treatment. Also, a large number of papers have discussed safety hazards to the eye and the skin at high power levels of laser radiation, indicating thresholds for injury and long-term disease. Therefore, for the safe use of laser treatment in the future there is a real need to agree on the problem on an international basis, to define the effective dose of laser radiation for each individual type of interaction, and to describe an appropriate measurement technique to predict the clinical result in terms of laser power administered, or, better yet, to develop an on-line feedback signal to control the laser output continuously in terms of the desired medical and biological result.

This Institute was devoted to establishing a basic platform of knowledge in this new field of research with a goal toward stimulating physicians and physicists to investigate the real mechanisms of laser-tissue interaction and further stimulating R\&D engineers in industry to develop smart systems with built-in process control, taking into account the results of laser hazards investigations, the basic knowledge of radiometric and photometric values, the experience of process modeling for various types of laser-tissue interaction, as well as results of investigations in the field of applied dosimetry.

As the editors for this Institute, we would like to express our special thanks to SPIE for organizing and supporting this endeavor. We are particularly indebted to Dr. Roy F. Potter, the general editor for the SPIE Institute Series, as well as to Ms. Dipl.-Phys. Brita Schaldach for organizing this event. Throughout the editorial process, Ms. Schaldach was the center for all communication among participants, and her skill and expertise have added greatly to the successful completion of this book. In addition, we thank Mrs. Schwark and Mrs. Schulz from the Laser-Medizin-Zentrum for editing and retyping the entire manuscript. We also express our gratitude to the Berlin Senate for sponsoring this Institute. With this wealth of support, we were able to assemble the most reknowned scientists currently working in this field and to establish a basic reference for the very important field of dosimetry of nonionizing radiation. This result could not have been possible without the extensive efforts required of each Institute participant. Finally, we thank Professor V. S. Letokhov and Dr. Franco Docchio for accepting our invitation to be guest contributors and for submitting valuable papers to complete the desired framework of this book.

Gerhard J. Müller

Laser-Medizin-Zentrum GmbH, Berlin (FRG)

David H. Sliney

U.S. Army Environmental Hygiene Agency 